material of the same character as before. In different directions a probe would pass to a depth of from two to four inches. He was in this general condition, growing steadily worse, when first seen by the reporter. At this time he moved in bed with difficnlty, was rery pale and emaciated, pulse weak, sweating easily, and looked much like one in an advanced stage of consumption. (on the right side. over the ribs, was a brawny, livid swelling, with several sinuses, into which the jrobe passed to different depths. The patient was coughing frecuently, and raising sputmm much like that of consumption. In incision into one of the little areas gave vent to sanguineous fuid, in which were little yellow particles, like minute particles of cheese. There was an extensive area of dulhess, the liver seemed much enlarged, and either it was enlarged upward or the lower portion of the lung was consolidated: still dullness, upon percussion, extended almost up to the line of the nipples. Microscopical examination of specimens of the sputum and of the discharge showed abundant actinomycotic fungi. An attempt at relief was made by resecting the three ribs most involved in the mass. A large portion of sloughing tissue was cut away with the ribs, and the sharp spoon was used freely without reaching the limit of the diseased mass. The collapse of the patient necessitated the suspension of the operation. Death from shock shortly afterward occurred.-Buffalo Medical and Suricial fonmal.

II. A Case of Actinomycosis of Intestine. By I)k. S. JAAche (Christiania). A coachman, thirty-eight years of age, had always been well, except two years before, when he sought medical aid on account of a digestive disturbance. 'This was relieved lyy diet, though his friends olsserved that he had been very aniemic: for several months. Two months before entering the hospital (November 28, i 888), he had noticed the dyspeptic symptoms more than ever, heaviness after meals, vomiting, an indefinite painfulness in both groins, rumning over to the insides of the thighs, while soon after he began to notice a disagreeable scratching feeling in the left side of 
the abdomen. Four weeks lefore entrance they increased in severity, and radiated ont toward the two iliac fosse, especially the left; they were not always present, but especially on violent exertion or heavy lifting. I uring the last four weeks he had slight nocturnal chills, being especially confmed to the legs, which could not be gotten warm, while the last few nights he had had sweats. 'lhree weeks lefore he had olserved a tumor, which rapidly increased in size, during the past fourteen days suddenly to rease growing. Great emaciation in the last two months had lecome especially noticealle during the past two weeks, with constipation. The tumor was situated to the left of the umbilicus, a circular prominence of eight centimetres diameter, with the skin of a normal appearance, displaceable and unattached to the growth. The surface gave one the impression of a round, somewhat uneven prominence, well circumscribed at all points, except below where it seemed to go down into the clepth of the pelvis, to be attached to the iliac fossa, ancl to be of an oblong shape. It was hard and of equal consistence, except a little spot in the centre, of the size of a puarter of a clollar, which was fluctuating. The tumor was immovalle, and only on deep pressure was it sensitive. In the right iliac fossa a second tumor, of the size of a hazel nut, immoveable and non-sensitive, was palpalsle in the depth of the pelvis. 'There were also other tumors, of the size of a bean, in the vicinity of this second one, but they were not pointed like the larger one. Both groins presented a group of enlarged glancls as large as a pea to that of a bean, and hard. ()n auscultation and percussion, coarse and sibilant râles were andihle in the upper parts of looth lungs. Urine normal. it trial puncture was made in the softened spot in the centre of the first tumor, and pus aspirated. No tubercle bacilli were to be made out, but on aclcling caustic potash to the pus. microscopically, several pale, rosette-like formations could be discerned, but no pronounced " actinomycosis rosettes" coukl be found. The tumor continued to increase in size, the area of fuctuation to widen, until the greater portion of the surface of the skin on the left side of the aldlomen, from the horcler 
of the rils to the inguinal fold, and from the linea alla to the anterior axillary line, was occupied. The skin over it was of a blush color, while the whole alswess was opened and scraped, the bottom being apparently formed by the transversalis fascia. A large quantity of pus was evaruated, containing numerous yellowish points, of the color of sulphur and of the size of a pin-heal. The cavity was packed with ioloform gauze and dressed. On changing the dressing the cavity was granulating. and with lut little secretion. He complained but little of his disease, and was only bothered by a hacking cough. The rhomehous and sibilant râles increased in number, his general condition became worse, welema of the malleoli and lumbar region set in, actinomyoutic rosettes were discovered, two alscesses developed in the right groin. which were opened, the dyspnocic attarks increased in severity, his strength became rery reduced, the cough grew olstinate. though the expectoration was not profuse, and, linally, on February 23 , I 889 . he died. The necropsy revealed an actinomycotic perityphlitis, with infiltration of the ilias fosse on both sides and the pulsis, associated with chronic peritonitis, a hepatic and perihepatic alscess, with perforation into the pleural cavity and conse(fuent double pleuritis and slight pericarditis. The cluration of the disease was, in all, five months. The diagnosis macle from the peculiarity of the tomor in having a lluctuating point in its centre and in its stalactite-like running to a point. The vermiform appendix was assumed to he the point of departure for the diseatse. Actinomycotic perityphlitis has recently leen described lo 1)r. ()tto Ian\%

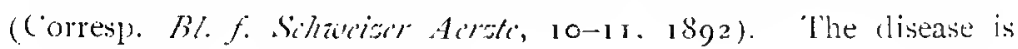

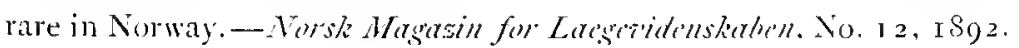

\section{Strangulated Femoral Hernia Involving only Part of Circumference of Bowel; Enterectomy; Enterorraphy;} Recovery. By R. Boklitit (Notaro. Italy). I peasant woman, fifty-four years of age, who had always been well and horne four children with normal lahors, noticed a nocle of the size of a nut in the right groin when twenty-eight years of age. It had remained 